\title{
Thermal, optical and spectroscopic characterizations of borate laser crystals
}

\author{
Chavoutier M., Jubera V., Veber P., Velazquez M., Viraphong O., Hejtmanek J., Decourt R., Debray J., Menaert \\ B., Segonds P., Adamietz F., Rodriguez V., Manek-Hönninger, Fargues A., Descamps D., Garcia A.
}

Abtract : The $\mathrm{Yb}$-content $\mathrm{Li}_{6} \mathrm{Ln}\left(\mathrm{BO}_{3}\right)_{3}(\mathrm{Ln}: \mathrm{Gd}, \mathrm{Y})$ solid solution has been investigated. Crystal growth has been successful for several compositions. A 22\% molar content of ytterbium ions was determined by chemical analysis (ICP). Physical properties relevant to laser operation like mechanical hardness, thermal expansion and thermal conductivity were measured on single crystals. Optical measurements, including refractive index and low temperature spectroscopy, were also performed. Finally, the effect of the $\mathrm{Y} / \mathrm{Gd}$ ratio is discussed.

\section{Introduction :}

The development of high average power lasers providing short pulses or continuous waves requires the characterization of thermal, mechanical as well as spectroscopic properties [1]. Thermal properties play a key role in achieving high average power lasers because if the material stores too much heat during the pumping process, a lack of efficiency and stability or even fracture behaviour of the laser crystal may occur. Thus a high thermal conductivity is mandatory for such laser applications. Mechanical properties are also important with respect to thermal shock resistance as well as for shaping and tailoring the material as a laser gain medium. However, all these properties are more or less modified when doping of the host compounds with rare earth ions is performed for laser operation. For example, thermal conductivity decreases with increasing rare earth ion concentration [2]. Consequently, the thermal, mechanical and optical properties across the $\mathrm{Yb}$-content $\mathrm{Li}_{6} L n\left(\mathrm{BO}_{3}\right)_{3}(\mathrm{Ln}$ : $\mathrm{Gd}, \mathrm{Y}$; this notation is used for $\mathrm{Li}_{6}\left(\mathrm{Gd}_{(1-x)} \mathrm{Y}_{x}\right)_{0.75} \mathrm{Yb}_{0.25}\left(\mathrm{BO}_{3}\right)_{3}$ compounds) solid solution have to be carefully studied if laser grade single crystals are to be obtained.

In this paper, we report the dependence on the gadolinium/yttrium ratio of selected thermal and mechanical properties. In Yb-content $\mathrm{Li}_{6} L n\left(\mathrm{BO}_{3}\right)_{3}(\mathrm{Ln}: \mathrm{Gd}, \mathrm{Y})$, low temperature photoluminescence spectra will be presented and commented on. These compounds crystallize in the monoclinic space group $P 2_{1} / c$ with $Z=4$ [3(a) and (b)]. According to the crystallographic data, rare earth ions occupy an eightfold site; the $\mathrm{LnO}_{8}$ octahedra are connected by a common corner along the $c$-axis (Fig. 1). Full solid solution from yttrium to gadolinium is observed. $\mathrm{Yb}^{3+}$ ions are the optically active species with a molar doping rate of $25 \%$.

Note: the term "doping" is used to differentiate the introduction the optical active element from the solid solution between yttrium and gadolinium.

In this work, the compositions $\mathrm{Li}_{6}\left(\mathrm{Gd}_{(1-x)} \mathrm{Y}_{x}\right)_{0.75} \mathrm{Yb}_{0.25}\left(\mathrm{BO}_{3}\right)_{3}$ with $x=0,0.25,0.5,0.75$ and 1 are investigated. For the remainder of this article, they will be identified as $L G B, L G 3 / 4 Y 1 / 4 B$, LGYB, LG $1 / 4 Y 3 / 4 B$ and $L Y B$, respectively. All the gadolinium containing crystal properties are reported here and compared to the $\mathrm{Yb}$ 26\%-content LYB crystal, which has already been proved to be promising for laser operation [4(a)-(c)].

\section{Material syntheses: crystal growth and characterization}

The compounds were first prepared by solid state reaction. Raw materials $\mathrm{Li}_{2} \mathrm{CO}_{3}, \mathrm{H}_{3} \mathrm{BO}_{3}, \mathrm{Y}_{2} \mathrm{O}_{3}, \mathrm{Gd}_{2} \mathrm{O}_{3}$ and $\mathrm{Yb}_{2} \mathrm{O}_{3}$ with a minimum purity of $99.98 \%$ were weighed in stoichiometric proportion according to the following reaction:

$$
\begin{gathered}
3 \mathrm{Li}_{2} \mathrm{CO}_{3}+3 \mathrm{H}_{3} \mathrm{BO}_{3}+\frac{0.75}{2}\left[(1-x) \mathrm{Gd}_{2} \mathrm{O}_{3}+x \mathrm{Y}_{2} \mathrm{O}_{3}\right]+\frac{0.25}{2} \mathrm{Yb}_{2} \mathrm{O}_{3} \\
\rightarrow \mathrm{Li}_{6}\left(\mathrm{Gd}_{1-x} \mathrm{Y}_{x}\right)_{0.75} \mathrm{Yb}_{0.25}\left(\mathrm{BO}_{3}\right)_{3}+3 \mathrm{CO}_{2} \uparrow+\frac{9}{2} \mathrm{H}_{2} \mathrm{O} \uparrow
\end{gathered}
$$

with $x=0,0.25,0.5,0.75$ and 1 .

The powder mixtures were first heated at $450{ }^{\circ} \mathrm{C}$ to remove water and then heated at $750{ }^{\circ} \mathrm{C}$ for $15 \mathrm{~h}$. The phase control of the products was achieved through X-Ray diffraction (XRD). In order to get a better insight into the crystal growth process, differential thermal analysis (DTA) measurements have been performed on a set of compositions, all of which display a melting point close to $860{ }^{\circ} \mathrm{C}$. As in the case of Ce-content LGB [5], the DTA analysis (DSC-DTA Netzsch 404 
Eos) of the ytterbium doped materials revealed that this borate series of compounds undergo high undercoolings typically around $200^{\circ} \mathrm{C}$ (Table 1). Hence, crystal growth requires substantial thermal gradients, which have been set in the vicinity of the solidification interface with values reaching $20^{\circ} \mathrm{C} \mathrm{cm}^{-1}$. The growth kinetics depends on the roughness of the interface [6], which itself is closely related to the so-called Jackson factor [7], defined as

$$
\alpha_{J}=\frac{\Delta H_{f}}{k T_{f}} f=3.9 f
$$

where $\Delta H_{f}$ denotes the melting heat, $k$ the Boltzmann constant and $f$ the ratio of the number of the nearest neighbour sites adjacent to an atom in the plane of the interface to the total number of nearest neighbours of an atom in the crystal [8]. $f$ usually lies between 0.5 and 5/6. 2D-mean field theory predicts roughening transitions for $\alpha_{\mathrm{J}}<2$, whereas in the 3DIsing model a critical $\alpha$-value of 3.2 is found. According to our calorimetric data, the crystals we investigated exhibit $\alpha$ values in the range of 1.95-3.25. Since they systematically underwent faceting, we believe their interface roughening transition is more likely to be due to a 2D-mean field behaviour.

The pre-melted product was loaded in a platinum crucible and placed inside a Czochralski pulling furnace. The compound was heated at $50{ }^{\circ} \mathrm{C}$ above the melting point in order to homogenize the composition of the melt. A seed oriented along the $c$-axis, corresponding to the direction of the rare earth polyhedron chain, was dipped inside the melt at a rotation rate of 5-7 rpm [5]. In order to improve the crystal quality, different growth processes were used. The pulling rate was chosen between 0.3 and $0.5 \mathrm{~mm} \mathrm{~h}^{-1}$ and the cooling rate was within the range of $0.3-1.0^{\circ} \mathrm{C} \mathrm{h}^{-1}$. After the growth, the crystal was annealed in a muffle furnace in order to reduce the stresses induced by the cooling. All the grown crystals showed a high optical quality zone, enabling the performance of optical tests. Their dimensions are more than $3 \mathrm{~cm}$ long and $2 \mathrm{~cm}$ wide in diameter. As an example, Fig. 2 depicts the LGB crystal that was grown using this method.

For each composition, XRD measurements were performed on crushed crystals (PANalytical X'Pert Pro diffractometer equipped with monochromatic $\mathrm{Cu} \mathrm{Ka1}$ radiation) in order to confirm the structure and determine the cell parameters, which were refined by a Lebail fit with the Fullprof programme [9]. With the substitution of yttrium for gadolinium, a contraction of the unit cell is observed (see Table 1$)$ according to the reduction of the cation radius $(r(\mathrm{Gd})=1.06 \AA$; $r(\mathrm{Y})=1.02 \AA ; r(\mathrm{Yb})=0.98 \AA)$.

Chemical analysis was performed by means of Inductively Coupled Plasma (ICP) spectroscopy on a Varian 720-ES instrument to determine the ytterbium concentration in the crystals. Results obtained are consistent with those of the cell parameters refinement performed on the XRD data. Due to differences between the rare earth elements, segregation occurs and the rare earth concentration is not constant along the crystal. For each crystal, the gadolinium, yttrium and ytterbium concentrations were determined as a function of distance from the seed along the $c$-axis. For all compositions, the gadolinium concentration is almost constant along the crystal and the quantity of yttrium ions is higher than expected at the top of the crystal (theoretical value in italic in Table 2). It decreases downwards below the expected theoretical value at the bottom of the crystal, whereas the ytterbium concentration increases along the crystal. This first observation reveals that the crystal growth process seems to favour the dissolution of yttrium ions. When the bulk composition is poorer in yttrium, the ytterbium content increases in the crystal.

In Table 2 the rare earth concentrations in the grown crystals are shown. All the measurements reported in this paper correspond to one piece of single crystal selected in the same area of the grown crystals.

\section{Mechanical and thermal properties}

\subsection{Hardness}

Knoop hardness measurements were performed on a Leica VMHT. The hardness of these materials is about 430HK0.025, as shown in Table 3. The observed differences between the crystals are not significant and are mainly due to the stress generated by the different growth protocols (cooling rate and pulling rate). This hardness corresponds to $4-5$ on the Mohs scale. Such results show that these materials are softer than other borates like GdCOB [10] or LGOB [11] (hardness of about 7 on the Mohs scale) or other well-known laser crystals like YAG [12] (hardness of about 
8-8.5), but similar to KYW [13] (hardness of about 4). Considering the structure description [3], one can imagine that the limiting factor arises from the borate groups located between $\mathrm{LnO}_{8}$ chains, which introduce weaknesses.

\subsection{Thermal expansion}

XRD measurements at different temperatures were performed in the 300-973 $\mathrm{K}$ temperature range on an undoped $\mathrm{Li}_{6} \mathrm{Gd}\left(\mathrm{BO}_{3}\right)_{3}$ crystal (LGB) and in the $20-300 \mathrm{~K}$ temperature range on the $\mathrm{Yb}(26 \%)$-content LYB crystal (Fig. 3a). The thermal volume expansion of the pure LGB crystal is depicted in Fig. $3 b$.

As for $\mathrm{Yb}$ 26\%-content LYB, these measurements indicate a linear expansion of the unit cell before reaching the melting point. No structural change was observed on these borate matrices from 20 to $973 \mathrm{~K}$.

\subsection{Thermal conductivity and heat capacity}

Even in ytterbium doped laser materials where the pump wavelength is very close to the laser wavelength, high average power laser operation always entails a thermal load that must be removed from the crystal. As thermal inertia due to heat conduction is linked to heat capacity $C_{p}$ and thermal conductivity $\kappa$, a fine characterization of both properties is mandatory. Note that for borate compounds, the thermal conductivity is usually small. Parameters like the low crystal symmetry, the heavy molar weight of the elements and of course the doping rate contribute to a decrease of thermal conductivity. In these materials, the gadolinium phase exhibits a larger molar weight than the yttrium one. Consequently, based on principal assumptions that govern thermal conductivity, LGB is expected to have a lower thermal conductivity than LYB at the same temperature. In addition, in these crystals the high doping rate (22\%) cannot be overlooked. To assess the thermal conductivity of doped compounds quantitatively, Gaumé et al. [2] have established a relationship linking thermal conductivity with the doping ion atomic weight. In order to keep thermal conductivity at its highest level, doping ions must substitute cations with comparable atomic weights. In the case reported by Gaumé et al., gadolinium gallium garnet (GGG) has a higher thermal conductivity than yttrium aluminium garnet (YAG) for an identical ytterbium substitution rate above 5\% [2]. The difference of molar masses between gadolinium ions $\left(M=157.25 \mathrm{~g} \mathrm{~mol}^{-1}\right)$ and ytterbium ions $\left(M=173.04 \mathrm{~g} \mathrm{~mol}^{-1}\right)$ is smaller than the difference between yttrium ions $\left(M=88.9 \mathrm{~g} \mathrm{~mol}^{-1}\right)$ and ytterbium ions. Hence, there should be a boundary ytterbium concentration from where LGB is expected to have a higher thermal conductivity than LYB. Consequently, the goal of this study is to see if the high substitution rate of ytterbium (22\%) will increase the thermal conductivity of LGB with respect to LYB crystals. Measurements of the thermal conductivities were performed on rectangular bars using a four points method. The thermal conductivity $\kappa\left(\mathrm{W} \mathrm{K}^{-1} \mathrm{~m}^{-1}\right)$ is deduced from the temperature difference $\Delta T(\mathrm{~K})$ between two sections of the crystal spaced by length $L(\mathrm{~m})$ measured by E-type thermocouples. One end of the crystal is heated by a micro-furnace, providing a heat flow $Q(W)$ across the rectangular shape of the sample with the cross section area $A\left(m^{2}\right)$ while the cold end is held at the sink temperature $T(\mathrm{~K})$. The thermal conductivity was calculated for each temperature using the following relation after a careful correction of radiative losses and parasitic heat flow via thermocouples and leads:

$$
\kappa(T)=\frac{Q}{A} \frac{L}{\Delta T}
$$

Measurements were performed along the b-axis for Yb-LYB, Yb-LGB and Yb-LGYB crystals. Fig. 4 shows a typical example of the evolution of the Yb-LGYB crystal thermal conductivity as a function of temperature.

On decreasing temperature below $300 \mathrm{~K}$, thermal conductivity increases and reaches a maximum at $25 \mathrm{~K}$. Then, thermal conductivity starts to decrease down to $\sim 3 \mathrm{~W} \mathrm{~m}-1 \mathrm{~K}-1$ at liquid helium temperature. This evolution is typical for crystalline materials in which an Umklapp scattering process is responsible for a decrease of thermal conductivity at high temperatures, whereas a decrease at low temperature is due to a drop of heat capacity [4(b)]. However the phonon mean free path at high temperature is in our case further depressed due to scattering of heat carrying phonons by optical modes associated with rigid $\mathrm{BO} 3$ groups. According to our opinion, this is the most effective process that limits thermal conductivity at high temperatures. 
For the solid solution, according to Table 3, the LYB crystal exhibits a higher thermal conductivity than the LGB crystal. At room temperature, the measured values have a relatively high uncertainty $( \pm 0.3 \mathrm{~W} \mathrm{~m}-1 \mathrm{~K}-1)$ and, consequently, the observed differences should be considered with precaution. In comparison with other borates like GdCOB (2.1 W m-1 K-1) [14] or BOYS $(1.8 \mathrm{~W} \mathrm{m-1} \mathrm{K-1)} \mathrm{[15],} \mathrm{the} \mathrm{thermal} \mathrm{conductivities} \mathrm{are} \mathrm{slightly} \mathrm{better} \mathrm{for} \mathrm{the} \mathrm{yttrium} \mathrm{phase}$ as well as for the gadolinium phase.

In order to complete the basic thermal characterization the heat capacity measurements were also performed on ytterbium doped LGB, LGYB and LYB crystals. The results are reported in Table 3 and the three compounds investigated show the same heat capacity. To conclude, the thermal properties are very close with a small improvement for the LYB compound.

\section{Optical and spectroscopic properties}

\subsection{Refractive index measurement}

Belonging to the biaxial optical class, the optical properties of monoclinic crystals are governed by the dielectric constant $\varepsilon_{r}$, which is a complex second order tensor. It is well known that the orthogonal frame, where the real part of $\varepsilon_{r}$ is diagonal, is the dielectric frame, or the optical frame, labelled $(X, Y, Z)$. The crystallographic frame is only linked to the dielectric frame for monoclinic crystals by the $b$-axis which is collinear with the $Y$-axis. The $X$ - and $Z$-axes are located in the same plane as that of the $a$ - and $c$-axes, which is perpendicular to the $b$-axis. The surface index of biaxial crystals in this dielectric frame is composed of two layers corresponding to the propagation of two polarization modes. Their values along the three main axes of the dielectric frame are the three main refractive indices $n_{X}, n_{Y}$ and $n_{Z}$.

We performed refractive index measurements on a piece of an orthogonal parallelepiped oriented along $(I, J, K)$, an orthogonal frame. We used our generalized ellipsometric technique coupled to a continuous wave laser emitting at $532 \mathrm{~nm}$ and the data analysis relies on an original method we developed [16]. It is based on a transfer matrix formalism that can handle quite complicated problems with ease and clarity like the study of anisotropic planar structures.

Hence, the four components of the dielectric matrix $\left(\varepsilon_{\| 1}, \varepsilon_{J J}, \varepsilon_{K K}, \varepsilon_{I K}=\varepsilon_{K I}\right)$, with respect to the monoclinic crystal axes, were obtained using an extended Brewster angle reflection method over a wide $\theta$ range of $\pm\left[10^{\circ}, 80^{\circ}\right]$.

Reflected p-polarized intensities in the $I J$-plane with incidence along the $J$ direction, called hereafter $R_{p}(I, J)$-J, have been recorded (Fig. 5). Six possible schemes for each crystal have been performed, i.e. $R_{p}\left(n_{J}, n_{l}\right)-I, R_{p}\left(n_{K}, n_{l}\right)-I$, $R_{p}\left(n_{l}, n_{J}\right)-J, R_{p}\left(n_{K}, n_{J}\right)-J, R_{p}\left(n_{l}, n_{K}\right)-K, R_{p}\left(n_{J}, n_{K}\right)-K$ and the six corresponding patterns have been fitted together to obtain the four components of the dielectric matrix. This original procedure minimizes the errors, and thus the accuracy of the obtained main values of refractive index from these ellipsometry measurements is better than 0.01 . Finally, the obtained dielectric matrix (defined with respect to the monoclinic frame) has been diagonalized in order to give the optical index of refraction in the optical frame at $532 \mathrm{~nm}$. The results are shown in Table 4.

The major variation of refractive index is observed on the ny values, which is coherent with the crystal layered structure since it corresponds to an excitation and response along the b-axis (Y-axis), i.e. perpendicular to the layers defined by the (ac) planes, which contain the LnO8 polyhedra chains.

Note: evolution of the $\mathrm{nx}$, ny and $\mathrm{nz}$ indexes indicates that part of the refined data might be overestimated because of the poor quality of some of the experimental patterns (Yb-LGB composition).

\subsection{Spectroscopic measurements}

The goal of these preliminary spectroscopic measurements is to check if the modification of composition induces changes on local symmetry around the ytterbium ions. Low temperature measurements are required to achieve good resolution of the spectra and to avoid thermally activated transitions. Transmission measurements have been performed with unpolarized light on the crystals. The absorption spectra were recorded using a double beam spectrophotometer (CARY 5000-UV-vis-NIR) between 850 and $1100 \mathrm{~nm}$. All the emission spectra were performed on powders (crushed crystal) and were recorded using a spectrofluorometer (Fluorolog 3 Horiba-Jobin Yvon) connected to an InGaAs detector using a $932 \mathrm{~nm}$ laser diode as excitation source. The low temperature measurements were recorded on the same equipment with an optistat Oxford Instrument cryostat cooled by a liquid helium circuit. 
Single crystal absorption and crushed crystal emission spectra were recorded at $15 \mathrm{~K}$ for each composition ([Fig. 6] and [Fig. 7]) to determine the $\mathrm{Yb}^{3+}$ energy level diagram in each crystal. The gadolinium ion has a bigger radius than the yttrium ion; consequently the ion radius difference may induce a distortion of the rare earth polyhedron, which is likely to affect the crystal field around the ytterbium site. The identification of ${ }^{2} F_{5 / 2}$ and ${ }^{2} F_{7 / 2}$ transition lines was labelled with the ground state component as number 1 and the highest excited state as number 7 . The absorption intensity in the spectra of Fig. $6 \mathrm{~b}$ is shifted in order to better visualize the expected wavelength shifts.

Surprisingly, the peak positions and the total splitting of the spectra do not change with composition. The lack of modification indicates that the substitution of yttrium by gadolinium is not sufficient to induce a strong modification of local symmetry around the ytterbium ion. Assignments of the peaks have been done according to the energy level structures determined in Refs. [17(a) and (b)]. The total splittings of the ${ }^{2} F_{5 / 2}$ and ${ }^{2} F_{7 / 2}$ multiplets amount to 544 and $687 \mathrm{~cm}^{-1}$, respectively. Furthermore, in both absorption and emission spectra, two lines (A and B) associated with transitions between the levels 1 and 5 are detected for each composition. The presence of a second emission of ytterbium ions was first reported by Brenier et al. [17(b)]. Complementary experiments seem to indicate that the second emission is related to the crystal growth process and suggest that it arises from the existence of $\mathrm{Yb}-\mathrm{Yb}$ ion pairs.

\section{Conclusion}

This paper investigated the characterization of mechanical, thermal and optical properties of $\mathrm{Yb}$-content $\mathrm{Li}_{6} \operatorname{Ln}\left(\mathrm{BO}_{3}\right)_{3}$ ( $L n: \mathrm{Gd}, \mathrm{Y}$ ) single crystals grown by the Czochralski method. The thermal conductivity varies from 1.6 to $2.9 \mathrm{~W} \mathrm{~m}^{-1} \mathrm{~K}^{-1}$ for the gadolinium and yttrium-based phases, respectively, whereas the hardness of the crystal does not depend on composition. The modification of composition does not change the melting point temperature, and large undercoolings have been observed. Good knowledge of these thermal properties allowed us to improve the crystal growth process. The introduction of gadolinium in the matrix results in an expansion of the unit cell parameters, which in turn implies an increase of the $L n-O$ bond lengths. Surprisingly, the luminescence spectra do not reflect these structural distortions. Crystal field effects around the ytterbium ions seem to be identical for the whole solid solution. The energy assignment of the crystal field components is similar to that of the yttrium-based phase. The low temperature luminescence spectroscopy has also put in evidence a non-negligible second emission of ytterbium ions, likely to be due to the formation of the $\mathrm{Yb}-\mathrm{Yb}$ pairs. Further optical characterizations will be performed on single crystals, including laser tests.

\section{Acknowledgments}

The authors thank M. J.-P. Manaud for his helpful advice on the Knoop test. This work was supported by Conseil Régional d'Aquitaine (Contract no. 20071101024), the CNRS and the GIS AMA. Marie Chavoutier is the holder of a Ph.D. thesis fellowship from Conseil Régional d'Aquitaine.

\section{References}

1) F. Druon, F. Balembois and R. Georges, C. R. Phys. 8 (2007), pp. 153-164.

2) R. Gaumé, B. Viana, D. Vivien, J.-P. Roger and D. Fournier, Appl. Phys. Lett. 83 (7) (2003), pp. 1355-1357.

3)(a)G.K. Abdullaev and K.S. Mamedov, Russ. J. Inorg. Chem. 22 (1977), pp. 1765-1766. (b)G.K. Abdullaev and K.S. Mamedov, Sov. Phys. Crystallogr. 22 (2) (1977), pp. 220-222.

4) (a)J. Sablayrolles, V. Jubera, J.P. Chaminade, I. Manek-Hönninger, S. Murugan, T. Cardinal, R. Olazcuaga, A. Garcia and F. Salin, Opt. Mater. 27 (2005), pp. 1681-1685. (b)J. Sablayrolles, V. Jubera, M. Delaigue, I. ManekHönninger, J.P. Chaminade, J. Hetjmanek, R. Decourt and A. Garcia, Mater. Chem. Phys. 115 (2009), pp. 512-515. (c)M. Delaigue, V. Jubera, J. Sablayrolles, J.P. Chaminade, A. Garcia and I. Manek-Hönninger, Appl. Phys. B 87 (4) (2007), pp. 693-696.

5) J.P. Chaminade, O. Viraphong, F. Guillen, C. Fouassier and B. Czirr, IEEE Trans. Nucl. Sci. 48 (2001), pp. 11581161.

6) D. Elwell and H.J. Scheel, Crystal Growth from High-temperature Solutions, Academic, London (1975).

7) K.A. Jackson, Liquid Metals and Solidification, ASM, Cleveland (1958).

8) X. Lu, Z. You, J. Li, Z. Zhu, G. Jia, B. Wu and C. Tu, Solid State Commun. 146 (2008), pp. 287-292.

9) J. Rodriguez-Carjaval, Fullprof: a programme for Rietveld refinement and pattern matching analysis, in: Collected Abstracts of the Powder Diffraction Meeting, Toulouse, France, 1990, vol. 127. 
10) G. Aka, A. Kahn-Harari, F. Mougel, D. Vivien, F. Salin, P. Coquelin, P. Colin, D. Pelenc and J.P. Damelet, J. Opt. Soc. Am. B 14 (9) (1997), pp. 2238-2247.

11) V. Jubera, P. Veber, M. Chavoutier, A. Garcia, F. Adamietz, V. Rodriguez, J.P. Chaminade and M. Velázquez, Cryst. Eng. Commun. 12 (2010), pp. 355-357.

12) L. Fornasiero, E. Mix, V. Peters, K. Petermann and G. Huber, Cryst. Res. Technol. 34 (2) (1999), pp. 255-260.

13) L. Tang, Z. Lin, L. Zhang and G. Wang, J. Cryst. Growth 282 (2005), pp. 376-382.

14) S. Chénais, F. Druon, F. Balembois, G. Lucas-Leclin, P. Georges, A. Brun, M. Zavelani-Rossi, F. Augé, J.P.

Chambaret, G. Aka and D. Vivien, Appl. Phys. B: Lasers Opt. 72 (2001), pp. 389-393.

15) S. Chénais, F. Druon, F. Balembois, P. Georges, R. Gaumé, P.H. Haumesser, B. Viana, G. Aka and D. Vivien, J. Opt. Soc. Am. B 19 (2002), pp. 1083-1091.

16) (a)V. Rodriguez and C. Sourisseau, J. Opt. Soc. Am. B 19 (2002), pp. 2650-2664. (b)V. Rodriguez, J. Chem. Phys. 128 (2008), p. 064707.

17) (a)J. Sablayrolles, V. Jubera, F. Guillen, R. Decourt, M. Couzi, J.P. Chaminade and A. Garcia, Opt. Commun. 280 (2007), pp. 103-109. (b)A. Brenier, A. Yoshikawa, K. lebbou, A. Jouini, O. Aloui-Lebbou, G. Boulon and T. Fukuda, J. Lumin. 126 (2007), pp. 547-550. 
Figures :

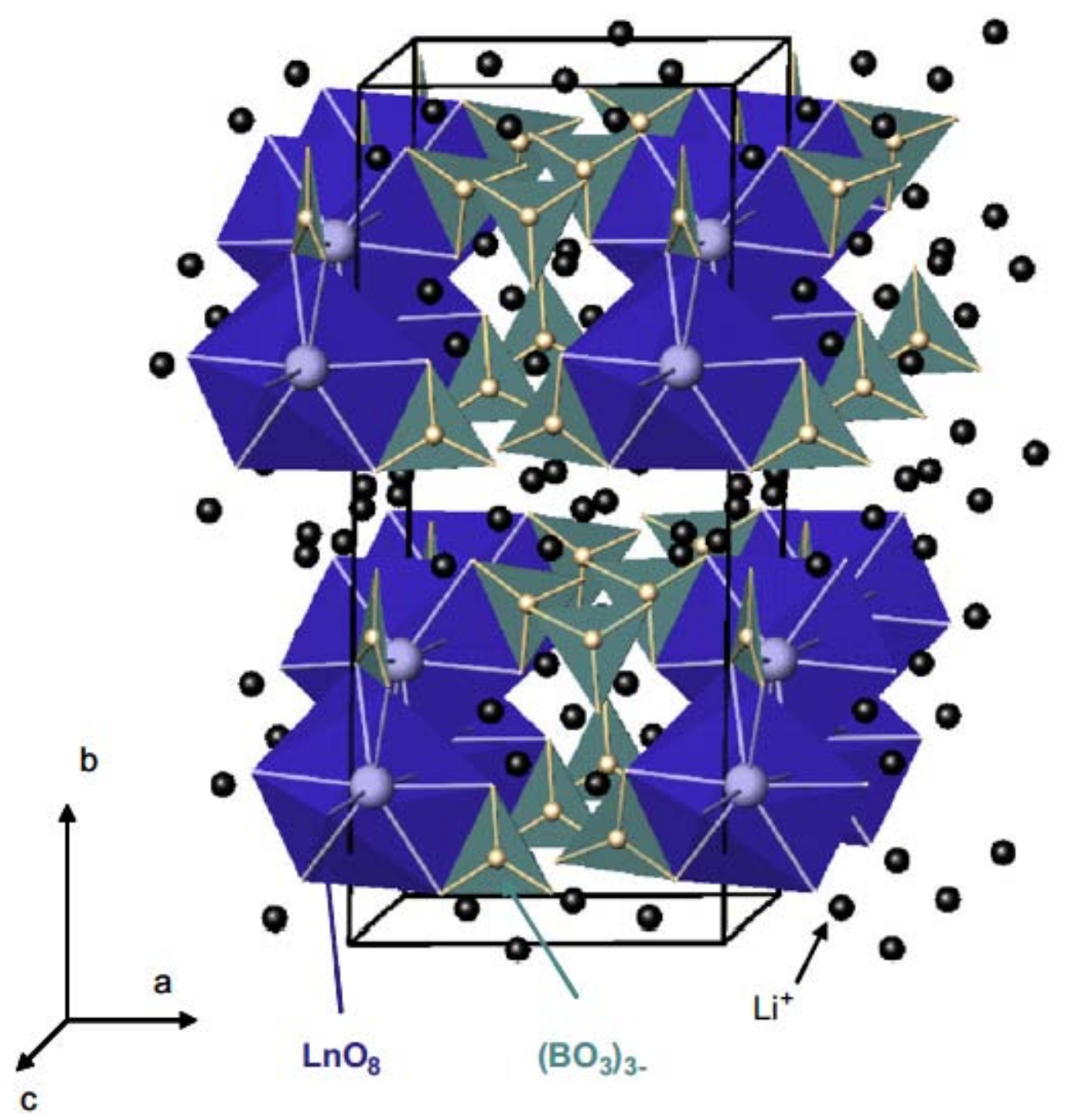

Fig. 1. Representation of the $\mathrm{Li}_{6} \operatorname{Ln}\left(\mathrm{BO}_{3}\right)_{3}$ compounds showing the $\operatorname{LnO} \mathrm{O}_{8}$ chains along the $c$-axis.

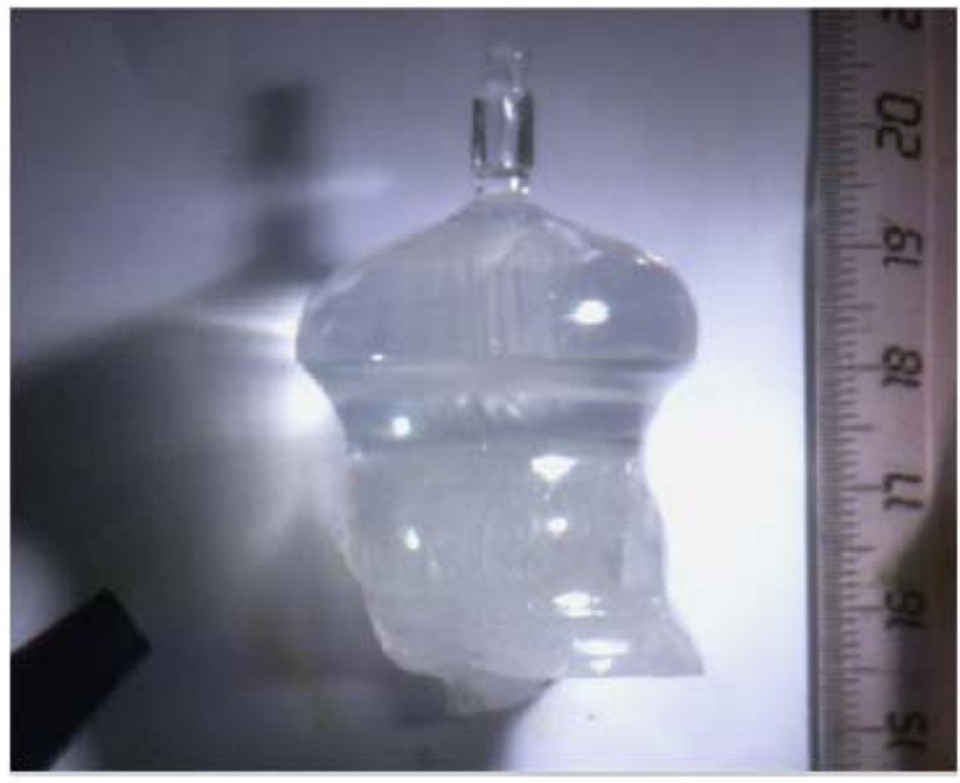

Fig. 2. Photography of an as-grown LGB single crystal. 

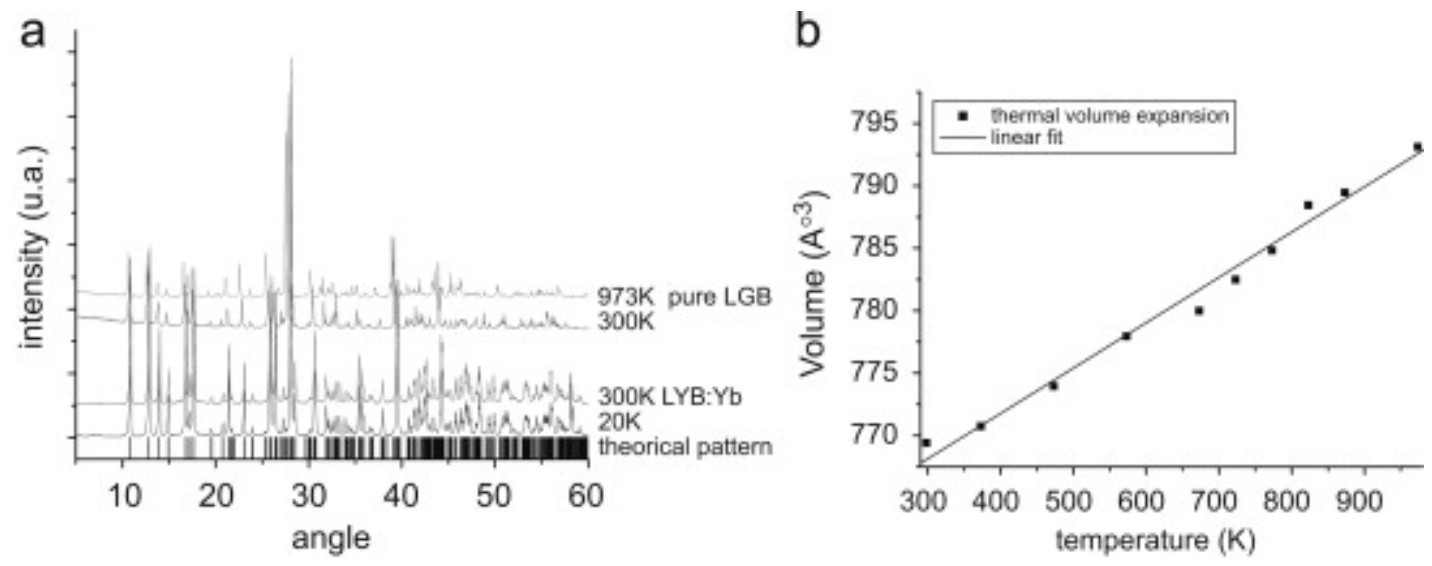

Fig. 3. (a) Powder X-ray diffraction patterns of $\mathrm{Yb}$ : $\mathrm{LYB}$ crystal at 20 and $300 \mathrm{~K}$ and of a pure $\mathrm{Li}_{6} \mathrm{Gd}\left(\mathrm{BO}_{3}\right)_{3}$ crystal at 300 and $973 \mathrm{~K}$. (b)Volume thermal expansion of pure $\mathrm{Li}_{6} \mathrm{Gd}\left(\mathrm{BO}_{3}\right)_{3}$ crystal as a function of temperature.

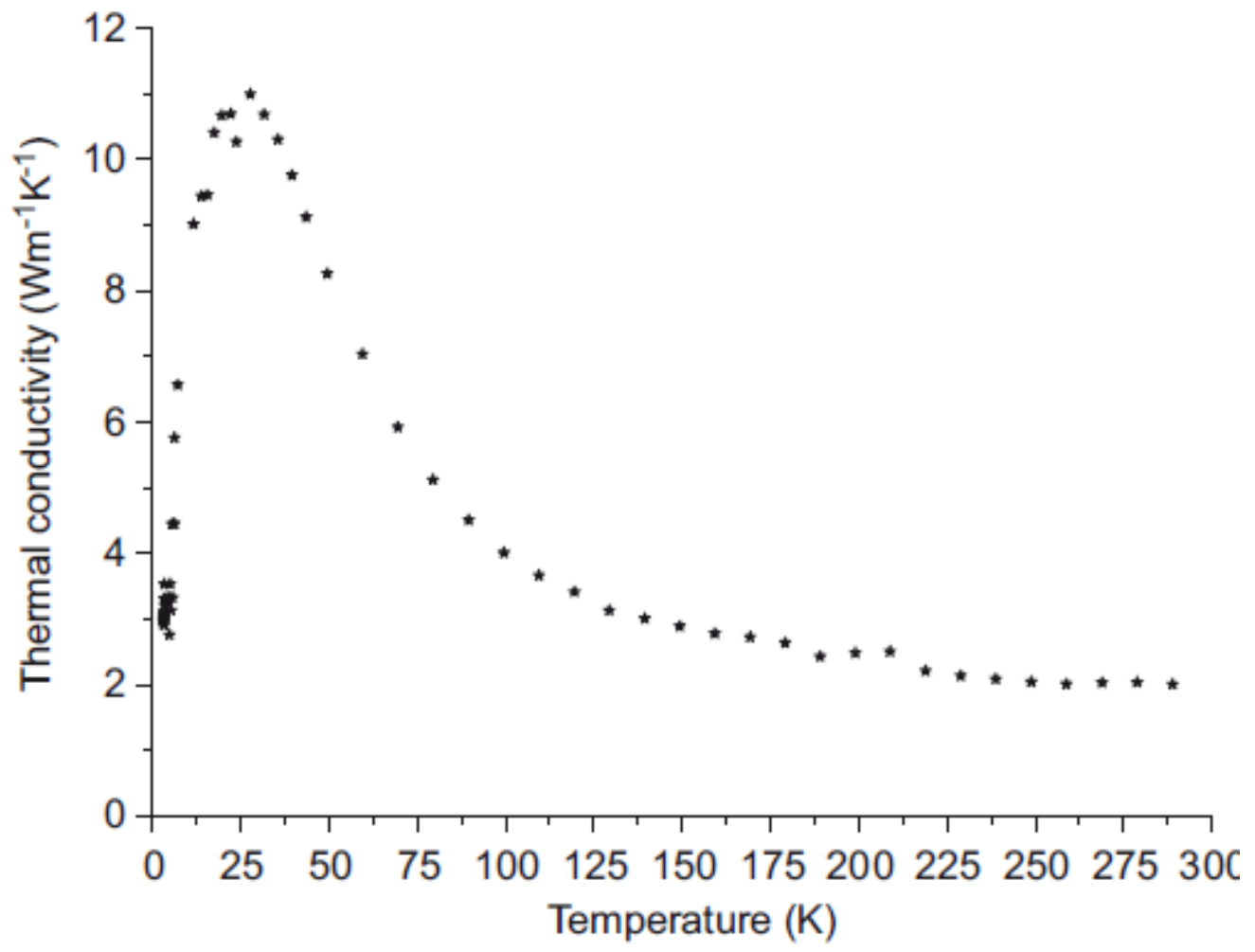

Fig. 4. Variation of the thermal conductivity with temperature along $b$-axis fo Yb-LGYB. 


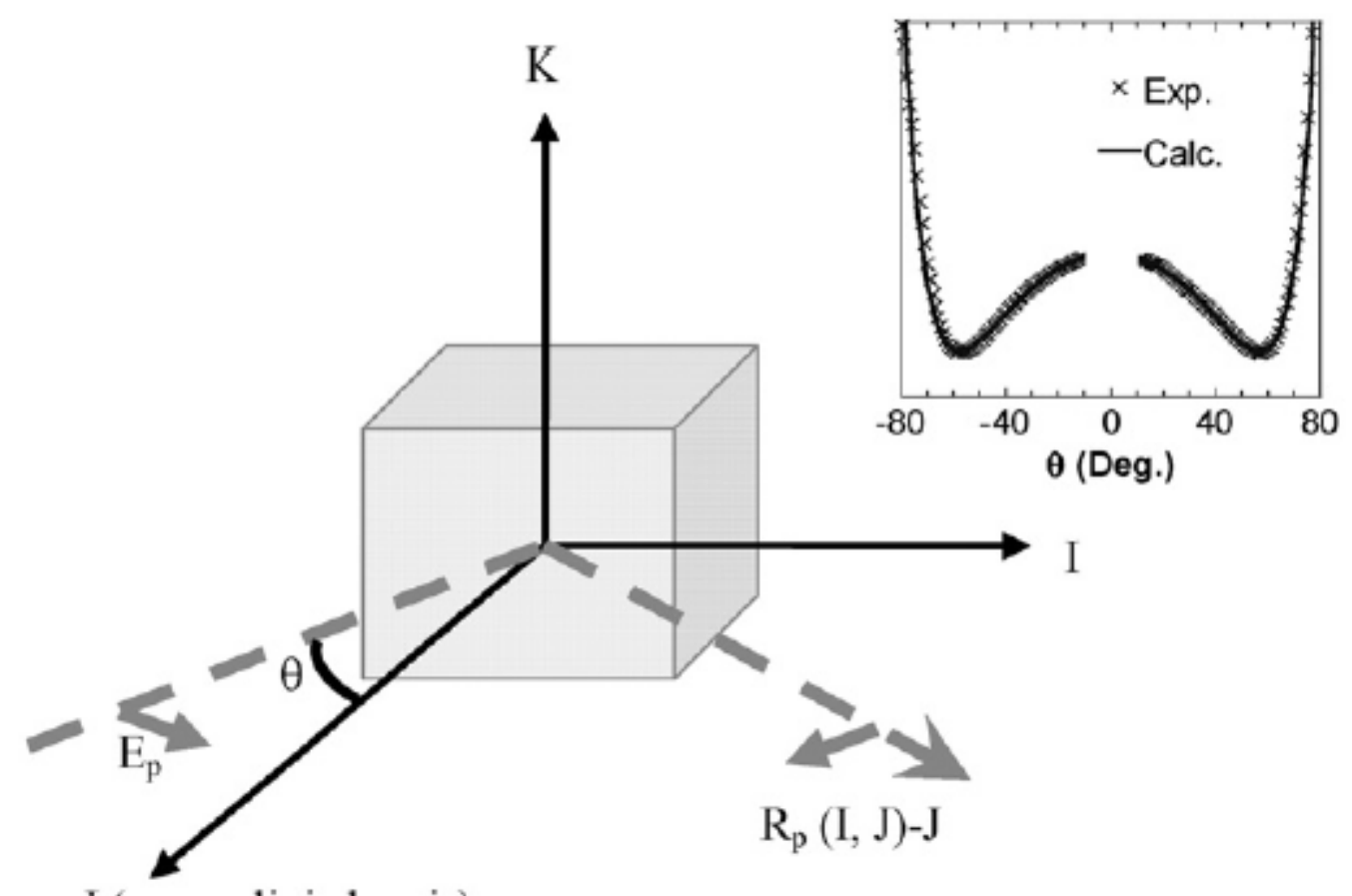

$\mathrm{J}$ (monoclinic b axis)

Fig. 5. Measurement of the reflected intensity $R_{p}(I, J)-J$ along the $J$ direction, as a function of the incidence angle $\theta$. The inset reports the corresponding experimental (crosses) and calculated (solid line) curves for $\mathrm{LG}^{3} / 4 \mathrm{Y}^{1 / 4 \mathrm{~B}}(25 \% \mathrm{Yb})$.

a

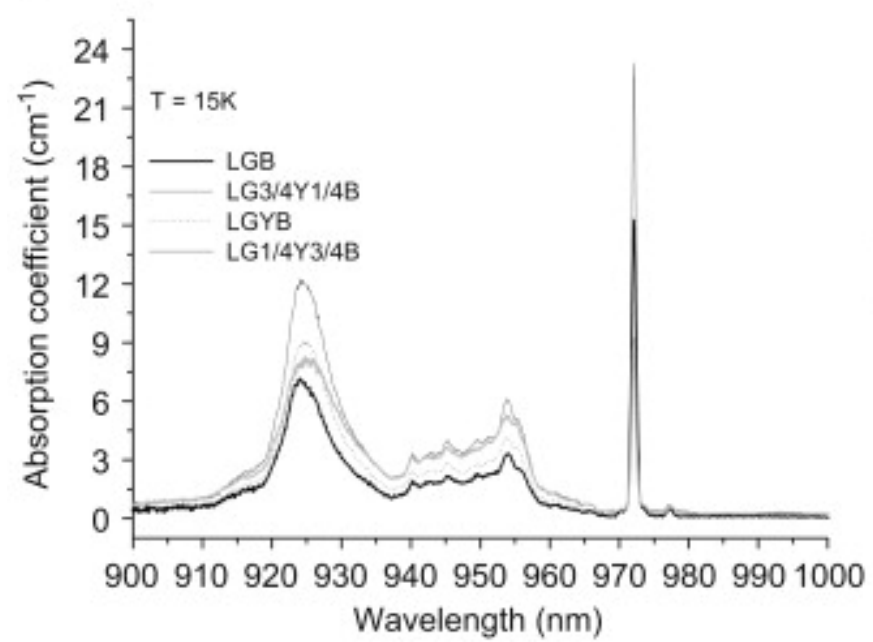

b

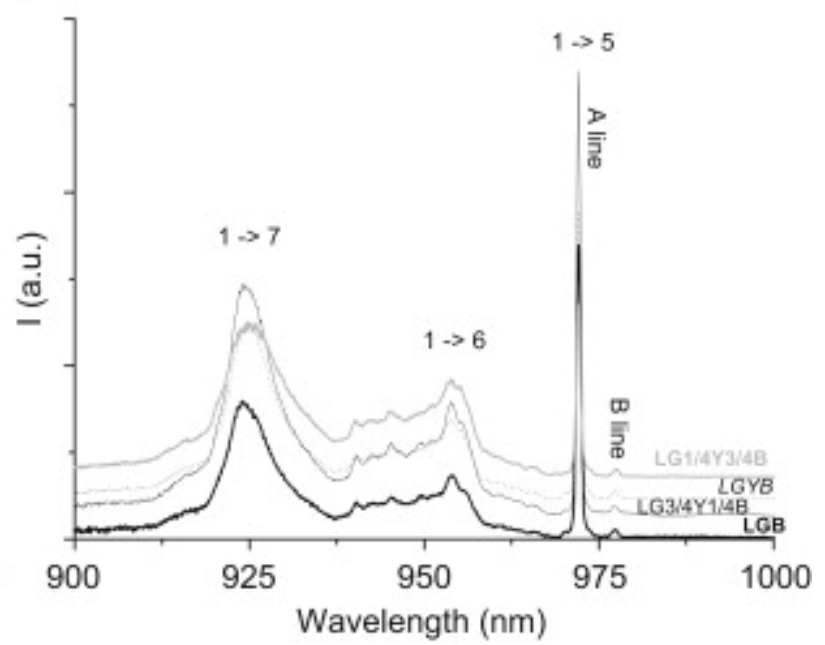

Fig. 6. (a) Absorption spectra of single crystals Yb 25\%-content LGB, Yb 25\%-content LG $3 / 4 Y^{1 / 4} / 4, Y b 25 \%$-content LGYB and $Y b$ 25\%-content $L G^{1 / 4} Y^{3} / 4 B$ at $15 \mathrm{~K}$ (no light polarization) and (b) shifted curves. 


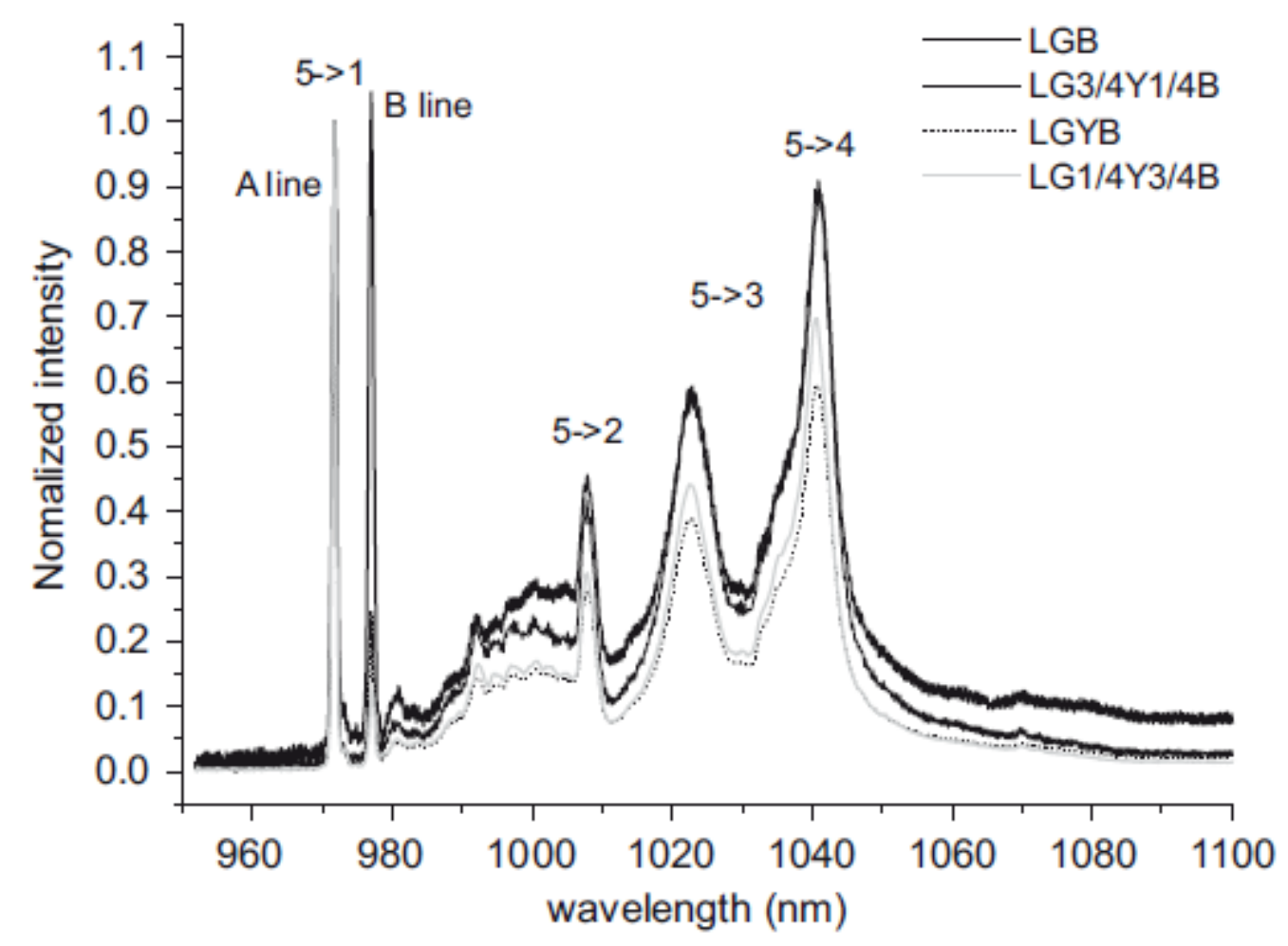

Fig. 7. Emission spectra of crushed crystals Yb 25\%-content LGB, Yb 25\%-content $\mathrm{LG}^{3 / 4} \mathrm{Y}^{1} 1 / 4 \mathrm{~B}, \mathrm{Yb} 25 \%$-content LGYB and Yb 25\%-content LG1/4Y $\mathrm{Y}^{3 / 4} \mathrm{~B}$ excited at $932 \mathrm{~nm}$ at $16 \mathrm{~K}$. 
Tableaux :

Table 1

Cell parameters and melting temperature.

\begin{tabular}{|c|c|c|c|c|c|c|c|c|}
\hline & \multicolumn{5}{|c|}{ Cell parameters } & \multirow[t]{2}{*}{$\boldsymbol{T}_{m}{ }^{\mathrm{a}}\left({ }^{\circ} \mathrm{C}\right)$} & \multirow[t]{2}{*}{$T_{\text {crys }}{ }^{\mathrm{b}}\left({ }^{\circ} \mathrm{C}\right)$} & \multirow[t]{2}{*}{$\Delta H_{f}\left(\mathrm{~kJ} \mathrm{~mol}{ }^{-1}\right)$} \\
\hline & $\boldsymbol{a}(\dot{\mathrm{A}})$ & $\boldsymbol{b}(\AA)$ & $c(\AA)$ & $\beta$ (deg.) & $V\left(\dot{A}^{3}\right)$ & & & \\
\hline LGB: Yb & $7.208(1)$ & $16.475(1)$ & $6.671(1)$ & $105.3(1)$ & 764.15 & 854 & 656 & 36.8 \\
\hline $\mathrm{LG}^{3} / 4 \mathrm{Y}^{1} / 4 \mathrm{~B}: \mathrm{Yb}$ & $7.198(1)$ & $16.460(1)$ & $6.660(1)$ & $105.3(1)$ & 761.05 & - & - & - \\
\hline LGYB: Yb & $7.192(1)$ & $16.446(1)$ & $6.653(1)$ & $105.3(1)$ & 759.03 & 857 & 668 & 34.7 \\
\hline$L G 1 / 4 Y^{3} / 4 B: Y b$ & $7.182(1)$ & $16.431(1)$ & $6.641(1)$ & $105.3(1)$ & 755.94 & - & - & - \\
\hline LYB:Yb & 7.171(1) & $16.409(1)$ & $6.630(1)$ & $105.3(1)$ & 752.62 & - & - & - \\
\hline
\end{tabular}

${ }^{a}$ Melting point

${ }^{\mathrm{b}}$ Crystallization temperature.

Table 2

Ytterbium, yttrium and gadolinium concentration (\% molar) at $0.5-1 \mathrm{~cm}$ below the initial seed.

\begin{tabular}{lllll}
\hline Exp. (theo.) & LGB: Yb & LG $3 / 4$ Y 1/4 B: Yb & LGYB: Yb & LG 1/4 Y $3 / 4$ B: Yb \\
\hline Gd & $78.5 \%(75 \%)$ & $59 \%(56.25 \%)$ & $39 \%(37.5 \%)$ & $20 \%(18.75 \%)$ \\
$Y$ & 0 & $19 \%(18.75 \%)$ & $40.6 \%(37.5 \%)$ & $58 \%(56.25 \%)$ \\
Yb $(25 \%)$ & $21.5 \%$ & $22 \%$ & $20.4 \%$ & $74(75 \%)$ \\
\hline
\end{tabular}

Table 3

Thermal and mechanical properties.

\begin{tabular}{|c|c|c|c|}
\hline & $\begin{array}{l}\text { Knoop hardness } \\
\text { (HK0.025) }\end{array}$ &  & $\begin{array}{l}\text { Heat capacity, } \\
T=293 \mathrm{~K} \\
\left(\mathrm{~J} \mathrm{~mol}^{-1} \mathrm{~K}^{-1}\right)\end{array}$ \\
\hline LGB: Yb & $430 \pm 30$ & 1.6 & 315 \\
\hline$L^{3}{ }^{3} / 4 Y 1 / 4 B: Y b$ & $400 \pm 30$ & - & - \\
\hline LGYB: Yb & $390 \pm 30$ & 2.0 & 313 \\
\hline LG1/4Y Y $3 / 4 B: Y b$ & $460 \pm 30$ & - & - \\
\hline LYB:Yb & - & 2.9 & 314 \\
\hline
\end{tabular}

Table 4

Optical properties: refractive index $(532 \mathrm{~nm})$.

\begin{tabular}{llll}
\hline & \multicolumn{2}{l}{ Optical index } & \\
\cline { 2 - 4 } & $\boldsymbol{X}$ & $\boldsymbol{Y}$ & $\boldsymbol{Z}$ \\
\hline $\mathbf{L G B}: \mathbf{Y b}$ & 1.54 & 1.57 & 1.64 \\
$\mathbf{L G}^{3} / \mathbf{4} \mathbf{Y} 1 / \mathbf{B}: \mathbf{Y b}$ & 1.56 & 1.68 & 1.67 \\
$\mathbf{L G Y B}: \mathbf{Y b}$ & 1.58 & 1.70 & 1.64 \\
$\mathbf{L G} 1 / 4 \mathbf{Y}^{\mathbf{3}} / \mathbf{B} \mathbf{B}: \mathbf{Y b}$ & 1.52 & 1.62 & 1.67 \\
\hline
\end{tabular}

